\title{
Preface to the special issue on business process management
}

\author{
Michael Rosemann • Michael zur Muehlen • \\ Marta Indulska
}

Published online: 19 October 2011

(C) Springer-Verlag 2011

It is our pleasure to present the special issue of Information Systems and e-Business on Business Process Management. This issue incorporates three select papers that originated from the BPM track of the European Conference on Information Systems 2008. Since then, the papers have gone through several rounds of review and revision, and represent a cross-section of research in the BPM area that touches, in particular, upon managerial and strategic issues.

The first paper entitled "Toward a theory of managing creativity-intensive processes: a creative industries study" by Stefan Seidel addresses the application of Business Process Management principles in settings where the creativity of process participants is more highly prized than the performance of highly structured and repetitive operations. Seidel studies processes in the film and visual effects industry and identifies several categories of uncertainty and risk that seem to characterize processes in these settings. His findings provide a foundation for further studies of processes in creative industries as well as processes where client involvement highly dictates the necessary steps and acceptable outcomes.

The second paper entitled "Formalizing process-based risk with Value-Focused Process Engineering" by Kristian Rotaru, Carla Wilkin, Leonid Churilov, Dina Neiger and Andrzej Ceglowski proposes a formal notation for the representation of process risk in goal-oriented processes. Drawing from the concept of value-focused process engineering, the authors extend the well-known Event-driven Process Chain modeling notation with constructs to capture risk objectives, adverse events, risk

\footnotetext{
M. Rosemann ( $₫)$

Queensland University of Technology, Brisbane, Australia

e-mail: m.rosemann@qut.edu.au

M. zur Muehlen

Howe School of Technology Management, Stevens Institute of Technology, Hoboken, NJ, USA

M. Indulska

The University of Queensland, Brisbane, Australia
} 
triggers and risk sources. The combination of a formal approach to capture risk and an easily accessible visualization of risk factors represents a significant opportunity for process designers that are tasked to demonstrate risk awareness to their clients.

The third paper entitled "Towards a business process-oriented approach to enterprise content management: the ECM-blueprinting framework" by Jan vom Brocke, Alexander Simons and Anne Cleven focuses on the preconditions for organizational success of Electronic Content Management (ECM) initiatives. The authors argue that misaligned processes are often the cause for unsuccessful ECM initiatives, rather than technical obstacles. The ECM-blueprinting framework proposed by the authors represents a five-step methodology for the successful identification and classification of information content in the enterprise, as well as the selection of technically appropriate ECM solutions for this content.

Combined, the three papers cover formal, empirical, and methodological work in the area of Business Process Management. They apply grounded theory, case study research, and design science approaches to arrive at their findings. Moreover, they demonstrate the practical relevance of academic research in the Business Process Management area. We hope you will enjoy reading the papers, as much as we enjoyed compiling and editing this special issue.

Michael Rosemann, Michael zur Muehlen, Marta Indulska

Guest Editors, Special Issue on Business Process Management 